\title{
Successful pregnancy in triplet with trap sequence
}

\author{
N. Hephzibah Kirubamani \\ Obstetrics and Gyneacology, Stanley Medical College \& former Superintendent i/c, \\ Govt. RSRM Lying- in Hospital, Chennai-600 013, India \\ hepsi1002@yahoo.co.in
}

\begin{abstract}
A case report is presented on twin reversal arterial perfusion in Triplet. The acardiac twin usually grows along with the pump twin, but due to inadequate perfusion it is unable to develop the structures necessary for life. In this condition zero intervention will be associated with almost $100 \%$ mortality rate of one or all fetuses. Hence in utero therapy was decided for our patient. In utero thermogeneic coil was applied on the blood vessel to Acardiac monster. As there was reanastomosis, again second coil was applied. Subsequently, the blood supply to Acardiac was totally cut off. The pregnancy was scanned weekly thereafter and both fetuses maintained good growth without any evidence of cardiac decompensation in the pump twin. The acardius remained stable in size. As patient developed hydrominios, Amnioreduction was done further to prevent preterm labour. Expectant management and dexamethasone courses weregiven. At 35 weeks of gestation and ultrasound revealed redistribution of arterial blood flow in the pump twin. In view of the risk of further haemodynamic instability of the pump twin, a Caesarean section was done and delivered two alive babies weighing $2.4 \mathrm{~kg}$ and $2.6 \mathrm{Kg}$ along with mumpified acardiac fetus.Since blood supply to acardiac twin was interrupted by 19 weeks our goal to get other two babies alive were achieved. This is the first case reported from Government R.S.R.M. Lying-in Hospital, Chennai, India.
\end{abstract}

Keywords: Triplet, Acardiac twin, Inutero therapy, Pump twin, Perfused twin

\section{Introduction}

Twin reversed arterial perfusion is a rare complication of monochorionic twin pregnancies, involving an acardiac twin whose structural defects are incompatible with life, and an otherwise normal "pump" twin. It occurs in 1\% of monochorionic twin pregnancies and in 1 in 35,000 pregnancies overall. TRAP syndrome causes mortality and deformities in all three fetuses. The acardiac twin grows along with the pump twin, but due to inadequate perfusion it is unable to develop the structures necessary for life, and presents with dramatic deformities. It is apparent that deoxygenated blood from the pump twin is perfused to the acardiac twin is called Perfused Twin and it is a true parasite.

\section{Pump twin}

Structurally the pump twin is generally normal, but due some of the related problems including the rapid growth of the acardiac twin, polyhydramnios, and heart failure due to high output and there is a high mortality rate for the pump twin. Available treatment includes, Conservative, Palliative and Causative treatment. Non Treatment will be associated with almost $100 \%$ mortality rate of one or all fetuses.

\section{Case Report}

Mrs. V. is G3P1L1A1: USG examination revealed Triplet with one fetus Acardiac. All three were alive in 17 weeks of pregnancy. Triamniotic Monochorionic and TRAP sequence was diagnosed. Detailed work up done along with fetal medicine specialist at Mediscan system. The acardiac twin grows along with the pump twin, but due to inadequate perfusion it is unable to develop the structures necessary for life (Fig. 1). In this condition, zero intervention will be associated with almost $100 \%$ mortality rate of one or all fetuses. Hence in utero therapy was decided for our patient. On 17th Jan when fetus was 17 week gestation under Scan guidance an in utero thermogeneic coil was applied on the blood vessel to Acardiac monster (Fig. 2). As there was reanastomosis again, second coil was applied on $27^{\text {th }}$ January. Subsequently, the blood supply to Acardiac was totally cut off. The pregnancy was scanned weekly thereafter and both fetuses maintained good growth without any evidence of cardiac decompensation in the pump twin. The acardius remained stable in size (Fig. 3). As patient developed hydrominios, Amnioreduction was done on $31^{\text {st }}$ Jan to prevent preterm labour (Fig. 4). Expectant management and dexamethasone courses were given. At

Fig. 1. Transabdominal USG shows a monochorionic monoamniotic Triplet with two normal fetus and abnormal fetus demonstrating heterogeneous echotexture, without any discernable internal organs

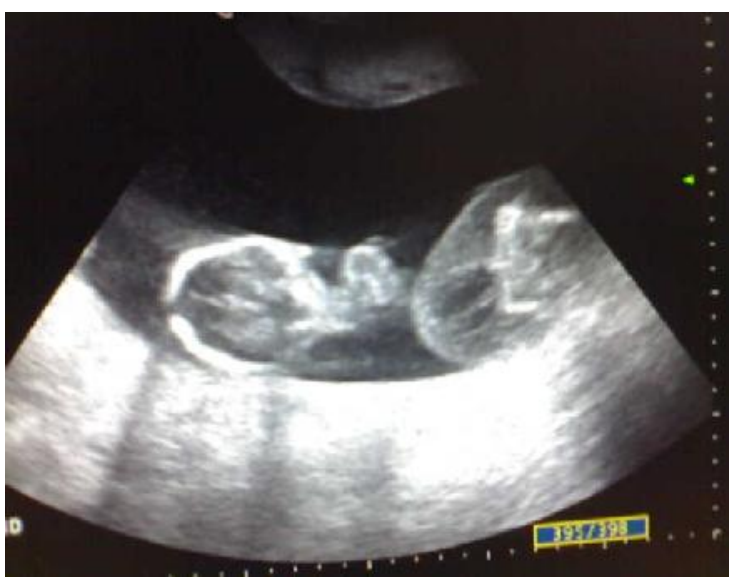

N.H.kirubaman Indian J.Sci.Technol. 
35 weeks of gestation, ultrasound examination revealed redistribution of arterial blood flow in the pump twin.

Fig. 2. Under scan guidance thermogenic coil was applied

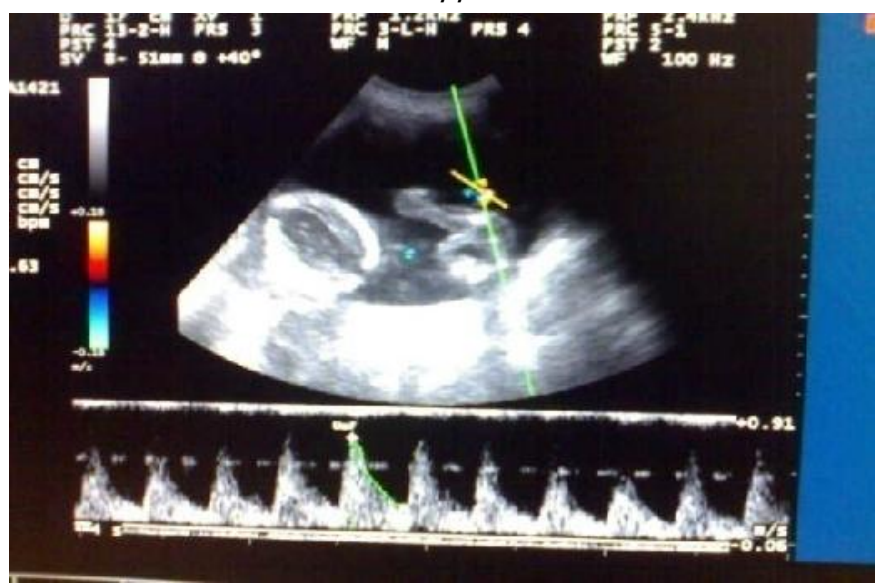

Fig. 3. Acardiac fetus following application of coil remained stable in size

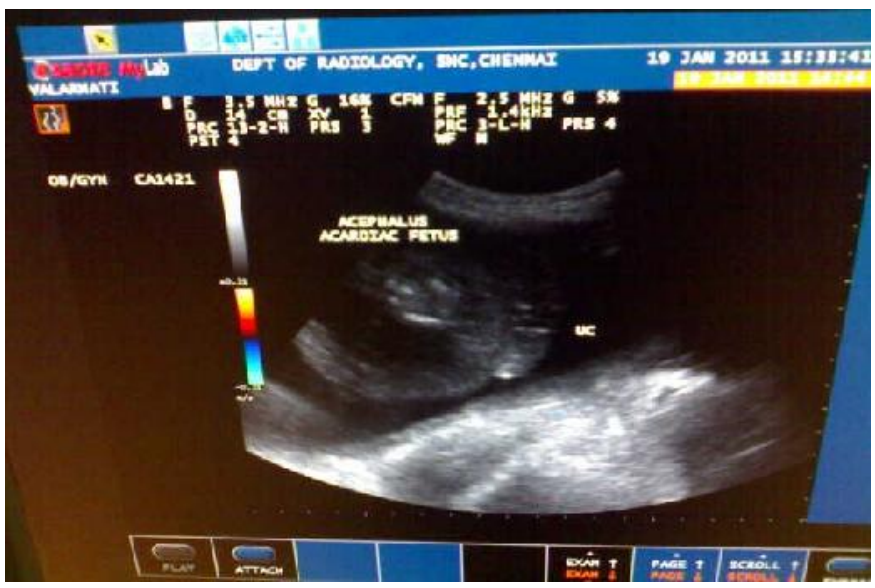

Fig. 4. As patient developed hydrominios Amnioreduction was done

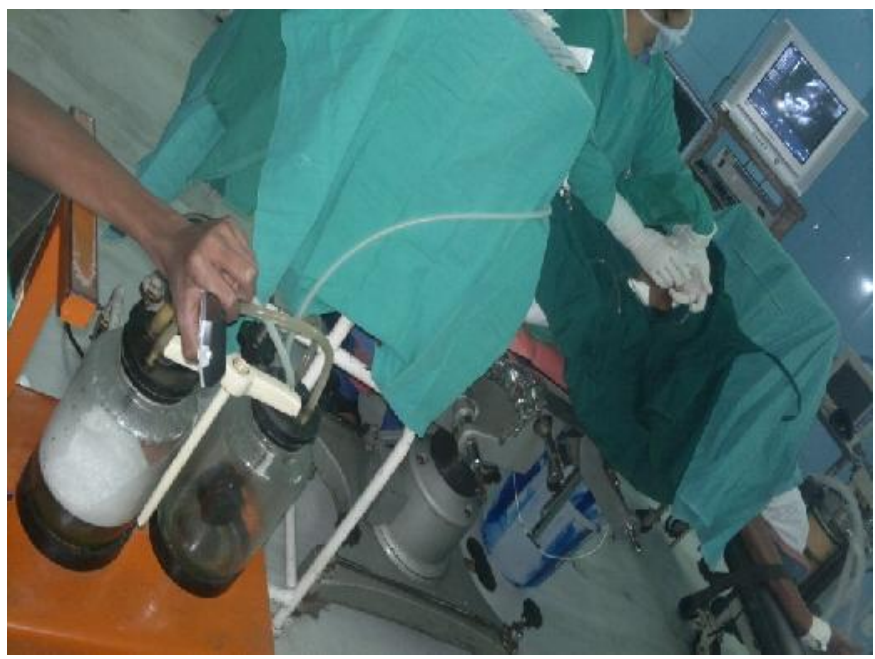

In view of the risk of further haemodynamic instability of the pump twin, a Caesarean section was done and Case Report COIndian Society for Education and Environment (iSee) "Triplet" http://www.indjst.org
Vol. 5 No. $9 \quad$ (Sep. 2012)

ISSN: 0974- 6846

Fig. 5. Two normal appearing new born

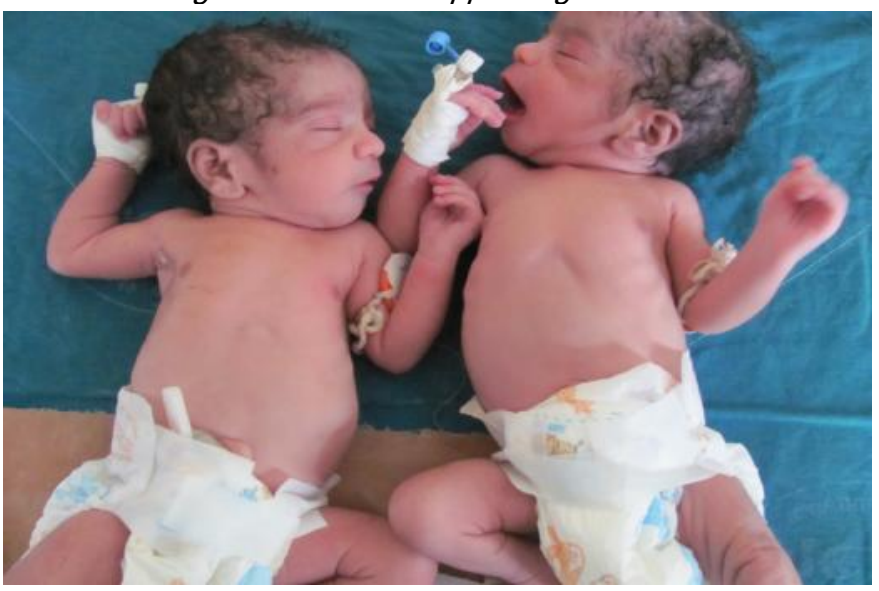

Fig.6. Single placenta with acardiac twin with two thermogenic coil

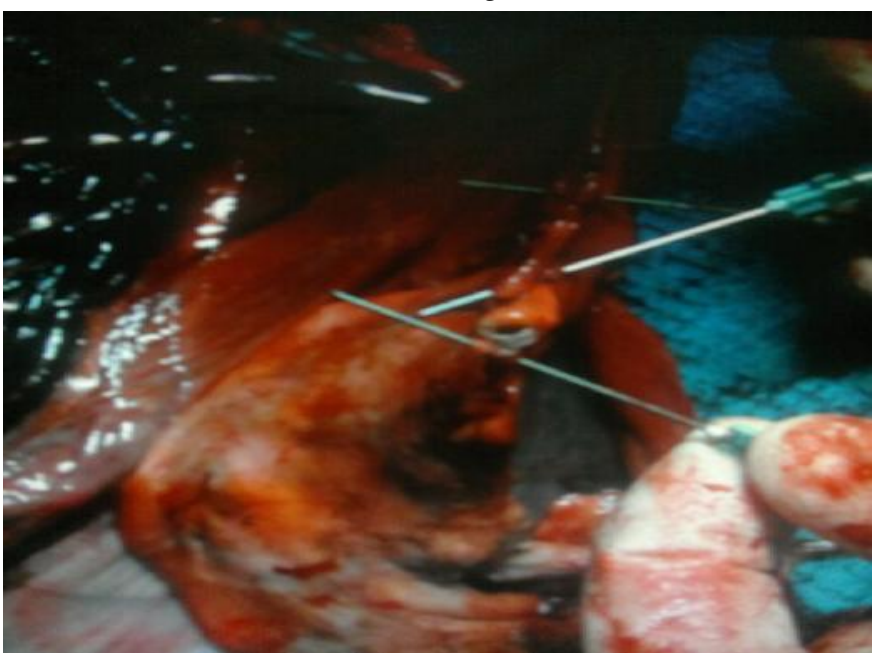

delivered two alive babies weighing $2.4 \mathrm{~kg}$ and $2.6 \mathrm{Kg}$ (Fig.5) along with mummified acardiac fetus (Fig.6).

\section{Discussion}

Incidence of multiple births in the developed world has increased dramatically over the past few decades from 1 in 100 to 1 in 60 to 1 in70 deliveries with a $40 \%$ increase in twinning rates and a three to fourfold rise in higher order multiple births. Minozygotic twins are at higher risk of complications and it is Chorionicity determines the outcome. The increased morbidity and mortality rates in monochorionic twins are primarily related to the angioarchitecture of the monochorionic placenta with its almost ever present vascular anastomoses. The Acardiac twin is perfused by Normal co-twin called as pump twin or donor twin by means of reversal of circulation through the large vein to vein anastomosis within the placenta (Pavlova et al., 1996). The natural history of the TRAP is poorly documented owing to the rarity of the disorder.The prediction of outcome for antenatally diagnosed TRAP is challenging. Realatively small acardiac mass is a good sign and larger acardiac mass will put greater hemodynamic strain on the Indian J.Sci.Technol. 
pump twin. Acardiac Twins (Krishna et al., 2005) are classified as Hemicardius if heart is incompletely formed; Holocardins if heart is absent; Acardius Anceps when head is poorly formed; Acardius Acephalus if head is absent; Acardius Amorphous if unrecognizable amorphous mass is present.

A cardiac fetus has $100 \%$ mortality (Baldwin, 1994). Pump twin is at risk of demise because of cardiac failure or pre-term delivery due to polyhydramnios (Baldwin, 1994; Sanjaghsaz et al., 1998). Fetal echocardiography is essential to evaluate pump twin for signs of cardiac failure.

The treatment range includes conservative, palliative and causative. Conservative consists of close antenatal surveillance, palliative involves serial amniodrainage and maternal administration of indomethacin for preterm labour and Digoxin for cardiac failure. Casuative treatment is to arrest the flow of blood to the acardiac twin by embolisation or fetoscopic cord ligation or fetoscopic or ultracound guided cord coagulation or ultracound guided application of thermogenic coil on the cord (Chandramouly \& Namitha, 2009). The Object of this case report is to discuss the importance of early use of ultra-sonogram in multiple gestations and its importance in diagnosing chorionicity, so that one can predict unique problems arising in monochorionic twin pregnancies. Doppler velocimetry is probably best tool to predict out come. Large difference in umbilical artery values suggest relatively little flow to acardiac twin, therby predicting favorable outcome.. Twin reversed arterial perfusion occurs in $1 \%$ of monochorionic twin pregnancies and in 1 in 35,000 pregnancies overall. TRAP syndrome causes mortality and deformities in all fetuses. Early Diagnosis of TRAP and appropriate treatment will definitely improve the outcome.

\section{Conclusion}

This challenging case is presented for its rarity and for its successful outcome because of early diagnosis and timely intervention. This case is the first case reported from Government R.S.R.M. Hospital, Chennai, India.

\section{Acknowledgement}

We thank Dr. S.Suresh, Director, Mediscan, Chennai for his valuable guidance and for the treatment which is done at free of cost.

\section{References}

1. Baldwin VJ (1994) Pathology of multiple pregnancies. NY: Springer-verlag.

2. Chandramouly $M$ and Namitha (2009) Case series: Trap sequence. Indian J. Rodiol. Imaging. 19, 81-83.

3. Krishna LG, Uppoor R, Shankar J and Sandhya (2005) Amorphous Acardiac parabiotic twins. Indian J. Radiol. Imag. 15(2), 267-270.

4. Pavlova M, Fouron Jc, Provlax F and Lessard M (1996) Importance of intrauterine diagnosis of rudimentary autonomic circulation in an acardiac twin. Arch. Mal. Coeur. Vaiss. 89(5), 629-632.
Vol. 5 No. $9 \quad$ (Sep. 2012)

ISSN: 0974- 6846

5. Sanjaghsaz H, Bayram MO and Qureshi F (1998) TRAP sequence in conjoined, Acardiac, Acephalic twins associated with normal triplet. A case report. $J$. Reprod. Med. 43(12), 1046-1050. 